\title{
Perancangan Sepeda Listrik Dengan Menggunakan Motor DC Seri
}

\author{
Hendarto Putra ${ }^{1}$ \\ ${ }^{1}$ Jurusan Teknik Elektro, Universitas Halu Oleo \\ Email Coprespondent Author : hendaro.uho@gmail.com
}

\begin{abstract}
Current technological and mobility developments have driven people to innovate and create energy-efficient, environmental friendly vehicles and can reduce dependence on oil fuel that will eventually run out. Currently began to emerge the means of transportation by using electrical energy as an alternative energy source of fuel oil such as electric bicycles. The purpose of this research is to design, to build, and to know how the electric bicycle system works with the utilization of generator, battery and electric motor as the driving source, then to know the amount of output power from the generator and to know the speed of motor rotation with different load. In this final project, the author has successfully designed and made an electric bicycle with driving system of dc series motor 24 volt, 350 watt, 14.4 ampere, $3000 \mathrm{rpm}$. The electric bicycle uses a 24 volt permanent dc magnet generator with 29 watt generated power to convert the kinetic energy from bicycle wheel rotation to electrical energy. The storage media of electrical energy on electric bike uses 4 batteries with a voltage of 12 volt -7.1 ah. From the results of electric bike testing and data analysis, obtained power output to drive electric bicycle with load $80.6=$ 316.6954 watt, load $85.6 \mathrm{~kg}=303.7732$ watt, load $90.6 \mathrm{~kg}=$ 294.5672 watt. The maximum speed of a no-load bike is 78.53 $\mathrm{m} / \mathrm{s}$. Average speed of the bike with load $80.6 \mathrm{~kg}=5.68 \mathrm{~m} / \mathrm{s}$, bike speed with load $85.6 \mathrm{~kg}=5.13 \mathrm{~m} / \mathrm{s}$, bike speed with load $90.6 \mathrm{~kg}=4.70 \mathrm{~m} / \mathrm{s}$.
\end{abstract}

Keyword -Electric Bike, Designing, DC Series Motor, DC Permanent Magnet Generator

Abstrak - Perkembangan teknologi dan mobilitas saat ini telah mendorong manusia untuk berinovasi dan menciptakan alat transportasi yang hemat energi, ramah lingkungan dan dapat mengurangi ketergantungan terhadap bahan bakar minyak yang sewaktu-waktu akan habis. Saat ini mulai bermunculan alat transportasi dengan menggunakan energi listrik sebagai sumber energi alternatif dari bahan bakar minyak diantaranya adalah sepeda listrik. Tujuan dari penelitian ini adalah untuk merancang, membuat, dan mengetahui cara kerja/sistem sepeda listrik dengan pemanfaatan generator, aki dan motor listrik sebagai sumber penggerak, kemudian untuk mengetahui besarnya daya yang keluar (output) dari generator tersebut dan mengetahui kecepatan putaran motor dengan beban yang berbeda-beda. Pada tugas akhir ini penulis berhasil merancang dan membuat sepeda listrik dengan sistem penggerak berupa motor dc seri 24 volt, 350 watt, 14.4 ampere, $3000 \mathrm{rpm}$. Sepeda listrik menggunakan generator dc magnet permanent 24 volt dengan daya yang dihasilkan 29 watt untuk mengkonversi energi kinetik dari putaran roda sepeda menjadi energi listrik. Media penyimpanan energi listrik pada sepeda listrik ini menggunakan 4 buah aki dengan tegangan masing-masing 12 volt -7.1 ah. Dari hasil pengujian sepeda listrik dan analisa data, didapatkan daya output untuk menggerakkan sepeda listrik dengan beban $80.6=316.6954$ watt, beban $85.6 \mathrm{~kg}=$ 303.7732 watt, beban $90.6 \mathrm{~kg}=294.5672$ watt. Kecepatan maksimum sepeda tanpa beban adalah $78.53 \mathrm{~m} / \mathrm{s}$. Kecepatan ratarata sepeda dengan beban $80.6 \mathrm{~kg}=5,68 \mathrm{~m} / \mathrm{s}$, kecepatan sepeda dengan beban $85.6 \mathrm{~kg}=5,13 \mathrm{~m} / \mathrm{s}$, kecepatan sepeda dengan beban $90.6 \mathrm{~kg}=4,70 \mathrm{~m} / \mathrm{s}$.

Kata kunci - Sepeda Listrik, Perancangan, Motor DC Seri, Generator DC Magnet Permanent

\section{PENDAhULUAN}

Alat transportasi di Indonesia juga semakin berkembang. Mobil dan sepeda motor adalah suatu alat transportasi yang ada di kalangan masyarakat. Energi listrik hasil konversi dari generator dimanfaatkan sebagai supply daya motor penggerak. Motor penggerak akan dikontrol oleh sebuah driver sehingga kinerja motor dapat berjalan dengan baik. Driver motor penggerak akan mengontrol kecepatan dan arah putaran motor penggerak. Untuk mendapatkan kinerja motor penggerak yang maksimal maka diperlukan suatu spesifikasi motor penggerak yang sesuai dengan kebutuhan sepeda listrik. Motor penggerak yang akan digunakan sepeda listrik yaitu jenis motor DC.

Motor yang digunakan pada tugas akhir ini adalah motor DCseri dengan magnet permanen pada statornya. Disebut demikian karena motor ini menggunakan dua atau lebih magnet permanen pada statornya. Sedangkan bagian motor yang berputar atau rotor terdiri dari lilitan yang akan terhubung pada suatu komutator mekanik melalui karbon brush.

Berdasarkan hal tersebut, maka penulis tertarik untuk mengambil melakukan penelitian tentang perancangan sepeda listrik dengan menggunakan motor DC seri. Sebagai bentuk implementasi pengetahuan yang didapatkan selama ini.

\section{RINGKASAN FORMAT MANUSKRIP}

Semua paragraf dalam teks ini, termasuk abstrak, nama gambar, dan referensi, harus dalam kondisi justified di ujung kiri dan kanan teks.

Dwi Sulistyanto (2008) dengan skripsinya yang berjudul "Rancang Bangun Sepeda Listrik Menggunakan Sistem Portable" memberikan metode perancangan sepeda listrik. Hasil dari rancang bangun sepeda listrik diharapkan menjadi acuan kedepannya agar pengembangan dan riset tentang sepeda listrikterus-menerus dilakukan untuk dapat mewujudkan sepeda listrik yang lebih baik lagi kedepannya dan memiliki kemampuan lebih dari penelitian sebelumnya. Perbedaan penelitian ini dengan sekarang yaitu dari model 
desain mekanik sampai dengan komponen sistem elektrik yang berbeda.

Benhur Nainggolan dan kawan - kawan (2016) dengan judul "Rancang Bangun Sepeda Listrik Menggunakan Panel Surya Sebagai Pengisi Baterai" pada penelitian ini mempunyai kesimpulan,daya motor listrik yang digunakandalam penelitian adalah 250 Wattdengan tegangan sumber sebesar 36volt DC, daya baterai yang digunakan sebagaisumber tegangan DC dalampenelitian adalah 324 watt-hour,daya motor listrik adalah 118,138 watt. Jika sepeda bergerak dengankecepatan $5,556 \mathrm{~m} /$ detik, maka jaraktempuh yang dapat ditempuh adalah54,855 km.Perbedaan penelitian ini dengan sekarang yaitu daya motor yang digunakan sebesar 350 watt dengan tegangan input 24 volt DC.

Dhimas Satria dan kawan - kawan (2017) dengan judul "Analisa Perhitungan Energi Listrik Pada Sepeda Listrik Hybrid"pada penelitian ini menggunakan metode menganalisa energi listrik pada sepeda listrik hybrid dengan variasi lintasan, beban, dankecepatan. Pengumpulan data yang diambil yaitu dari mengkombinasikan kondisi jalan yang menanjak, menurun, mendatar, perbedaan beban, dan perbedaan kecepatan.

\section{A. Rangka Alat}

Sepeda merupakan suatu alat yang di gunakan untuk mengangkut atau sebagai sarana transportasi yang ramah lingkungan, pada sepeda terdapat beberapa bagian komponen utama yaitu rangka, ban/roda, rantai, brake system(rem), saddle part, dan sistem kemudi

\section{B. Baterai}

Baterai adalah suatu proses kimia listrik, dimana pada saat pengisian/chargerenergi listrik diubah menjadi kimia dan saat pengeluaran/discharger energi kimia diubah menjadi energi listrik. Baterai (dalam hal ini adalah aki; aki mobil/motor) terdiri dari sel-sel dimana tiap sel memiliki tegangan sebesar $2 \mathrm{~V}$, artinya aki mobil dan aki motor yang memiliki tegangan $12 \mathrm{~V}$ terdiri dari 6 sel yang dipasang secara seri $(12 \mathrm{~V}=6 \times 2 \mathrm{~V})$ sedangkan aki yang memiliki tegangan $6 \mathrm{~V}$ memiliki 3 sel yang dipasang secara seri $(6 \mathrm{~V}$ $=3 \times 2 \mathrm{~V})$. Waktu

Waktu mereupakan ukuran suatu kejadian yang berurutan (ukuran relatif suatu kejadian). Waktu tidak memperhitungkan dalam ilmu mekanika statis.

\section{Motor listrik arus searah (DC)}

Motor listrik merupakan perangkat elektromagnetis yang mengubah energi listrik menjadi energi mekanik.Motor DC memerlukan suplai tegangan yang searah pada kumparan medan untuk diubah menjadi energi mekanik. Kumparan medan pada motor DC disebut stator (bagian yang tidak berputar) dan kumparan jangkar disebut rotor (bagian yang berputar). Jika terjadi putaran pada kumparan jangkar dalam pada medan magnet, maka akan timbul tegangan (GGL) yang berubah-ubah arah pada setiap setengah putaran, sehingga merupakan tegangan bolak-balik.

Untuk perhitugan motor penggerak :

1. Massa system kendaraan ditunjukkan pada persamaan 1 dan 2 .

$$
\begin{gathered}
M_{\text {tot }}=M_{s}+M_{e}+M_{p} \\
W_{\text {tot }}=M_{\text {tot }} \times g
\end{gathered}
$$

Dimana:

$M_{\text {tot }}=$ Massa total sepeda listrik $(\mathrm{Kg})$

$M_{s}=$ Berat sepeda $(\mathrm{Kg})$

$M_{e}=$ Berat peralatan $(\mathrm{Kg})$

$M_{p}=$ Berat pengendara $(\mathrm{Kg})$

$W_{\text {tot }}=$ Berat total sepeda listrik $(\mathrm{N})$

$\mathrm{g}=$ Gravitasi bumi $\left(9.8 \mathrm{~m} / \mathrm{s}^{2}\right)$

2. Daya mekanik

Untuk gaya normal ditunjukkan pada persamaan 3

$$
F_{N}=M_{\text {tot }} \times 9.81
$$

Untuk gaya gesek statis ditunjukkan pada persamaan 4

$$
F_{S}=F_{N} \times \mu s(0,7)
$$

Untuk gaya gesek kinetic ditunjukkan pada persamaan 5

$$
F_{k}=F_{N} \times \mu k(0,6)
$$

Torsi yang di perlukan untuk menggerakkan sepeda harus lebih besar dari pada,

$$
T_{s}>F_{s} \times R_{\text {roda }}
$$

Agar sepeda bergerak, makagaya pedal kaki harus lebih besar dari pada

$$
F>\frac{T_{s}}{R_{p-s}}
$$

Setelah sepeda bergerak, maka gaya $(\mathrm{F})$ yang di perlukan ditunjukkan pada persamaan 8 .

$$
F=\frac{F_{k} \times R_{p-s}}{R_{\text {madi }}}
$$

3. Torsi motor lostrik ditunjukkan pada persamaan 9

$$
T_{\text {motor }}=\frac{60 * P}{2 * \pi * n}
$$

Dimana :

$\mathrm{P}=$ daya motor $($ Watt $)$

$\mathrm{n}=$ putaran poros motor $(\mathrm{Rpm})$

4. Daya yang dihasilkan motor listrik untuk menggerakkan sepeda ditunjukkan pada persamaan 10 .

$$
P_{\text {out }}=9.8 \times \mu \times M_{\text {tot }} \times V_{\text {rata-rata }} \times \eta
$$


Dimana :

$\mathrm{M}_{\text {tot }} \quad=$ Massa total sepeda listrik $(\mathrm{kg})$

$\mu \quad=$ koefisien geser $(0,06)$

$\eta \quad=$ efesiensi mesin kerja

$\mathrm{v}_{\text {rata-rata }}=$ kecepatan sepeda $(\mathrm{m} / \mathrm{s})$

5. Kecepatan tempuh sepeda ditunjukkan pada persamaan 11.

$$
v=\frac{s}{t}
$$

Dimana :

$\mathrm{s}=$ jarak tempuh $(\mathrm{m})$

$\mathrm{v}=$ kecepatan sepeda $(\mathrm{m} / \mathrm{s})$

$\mathrm{t}=$ waktu tempuh $(\mathrm{s})$

\section{GeneratorDC Magnet Permanent}

Generator DC merupakan sebuah perangkat motor listrik yang mengubah energi mekanis menjadi energi listrik. Generator DC menghasilkan arus DC / arus searah.

\section{E. Rangkaian Rectifier}

Rectifier atau dalam bahasa Indonesia disebut dengan penyearah gelombang adalah suatu bagian dari rangkaian catu daya atau power supply yang berfungsi sebagai pengubah sinyal AC (alternating current) menjadi sinyal DC (direct current). Rangkaian rectifier atau penyearah gelombang ini pada umumnya menggunakan dioda sebagai komponen utamanya. Hal ini dikarenakan dioda memiliki karakteristik yang hanya melewatkan arus listrik ke satu arah dan menghambat arus listrik dari arah sebaliknya.

\section{F. Charge Control}

Charge controller adalah rangkaian elektronik yang mengatur proses pengisian aki atau rangkaian aki (battery bank). Tegangan DC yang dihasilkan oleh generator pada umumnya bervariasi 12 volt ke atas. Controler ini berfungsi sebagai alat pengatur tegangan aki agar tidak melampaui batas toleransi dayanya.

\section{METODE PENELITIAN}

Pada umumnya ada tiga metode yang dipakai dalam metode penelitian, yaitu metode survey, metode kasus (studi kasus), dan metode eksperimen. Pada penelitian ini digunakan metode eksperimen. Metode eksperimen yaitu melakukan penelitian dengan membuat sistem penggerak sepeda listrik dengan memodifikasi sepeda lipat dengan pemanfaatan generator magnet permanen dan aki sebagai sumber energi penggerak.

Adapun bagan alir penelitian dapat dilihat pada gambar 1 .

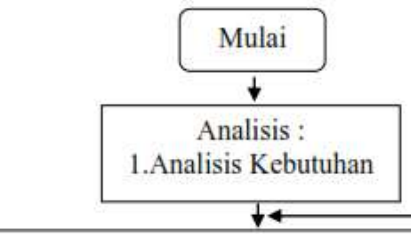

Gambar 1. Bagan alir penelitian

\section{A. Perancangan Alat}

Adapun gambar perancangan alat ditunjukkan pada gambar 2.

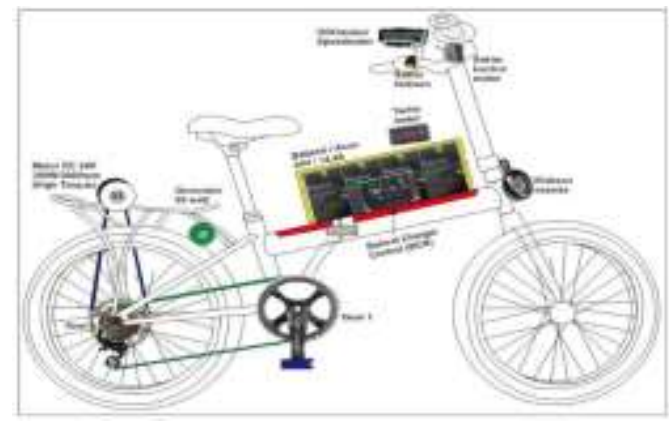

Gambar 2. Perancngan alat

\section{B. Blok diagram perancangan alat}

Blok diagram adalah sebuah metode yang dapat digunakan untuk menjabarkan sebuah sistem yang rumit. Dengan menggunakan blok diagram maka suatu system dapat dipartisi / dipecah berdasarkan fungsi dan kegunaannya. Tujuannya adalah agar lebih mudah untuk dipahami. Gambar 2 menunjukkan blok diagram alat .

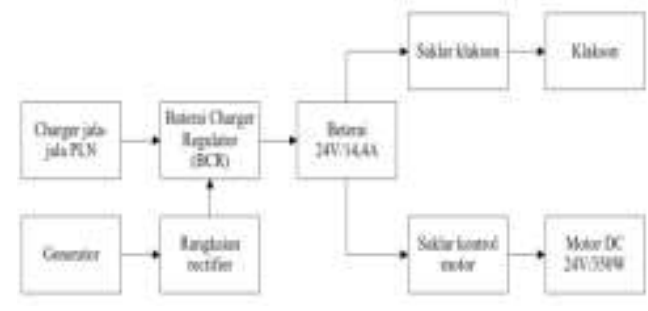

Gambar 2 blok diagram alat.

\section{Flowchart alat}


Flochart penelitian dari alat yang dibuat ditunjukkan pada gambar 3.

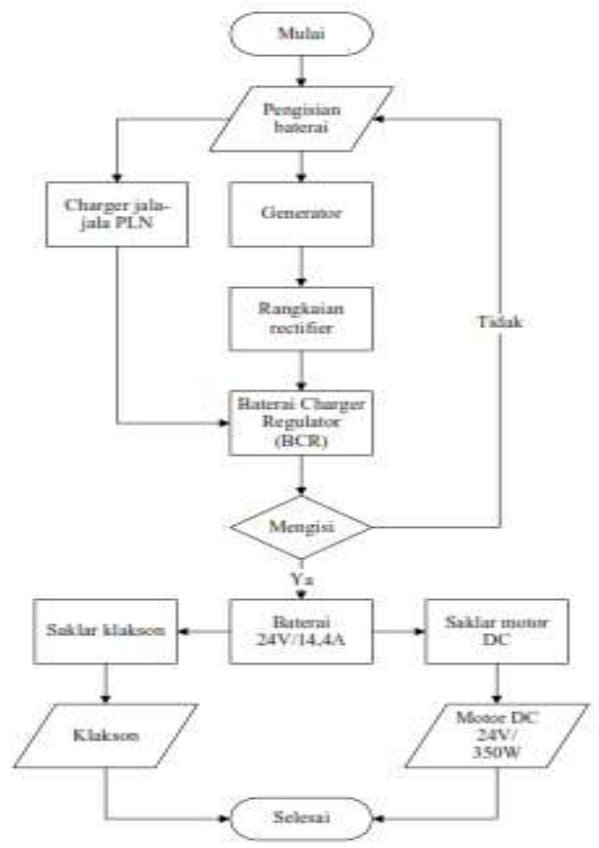

Gambar 3. Flowchart alat.

\section{HASIL DAN PEMBAHASAN}

\section{A. Spesifikasi sepeda listrik}

Adapun model kendaraan yang akan digunakan untuk sepeda listrik ini adalah sebagai berikut :

1. Sepeda Lipat:

- Panjang sepeda

$=100 \mathrm{~cm}$

- Lebar sepeda

$=54 \mathrm{~cm}$

- Tinggi sepeda

$=100 \mathrm{~cm}$

- Diameter ban sepeda

$=50 \mathrm{~cm}$

- Diameter gear sisi kiri

$=18 \mathrm{~cm}$

- Diameter gear sisi kanan

$=12 \mathrm{~cm}$

- Diameter gear pedal kaki

- Berat sepeda

$=20 \mathrm{~cm}$

$=20 \mathrm{Kg}$

2. Motor listrik:

- Panjang motor listrik

$=13 \mathrm{~cm}$

- Lebar motor listrik

$=10 \mathrm{~cm}$

- Tinggi motor listrik

$=10 \mathrm{~cm}$

- Diameter poros (gear)

$=6 \mathrm{~cm}$

- Berat motor listrik

$=2,5 \mathrm{Kg}$

- Tegangan listrik motor DC $=24 \mathrm{Volt}$

- Daya listrik motor DC $=350 \mathrm{~W}$

3. Generator DC Magnet Pernanent

- Panjang generator $=11,5 \mathrm{~cm}$

- Lebar generator $\quad=8,5 \mathrm{~cm}$

- Tinggi generator $=8,5 \mathrm{~cm}$

- Berat generator $=0,1 \mathrm{~kg}$
- Tegangan listrikgenerator $=24$ Volt

- Daya listrik generator = $29 \mathrm{Watt}$

4. Baterai/Aki

- Panjang baterai/aki $=26 \mathrm{~cm}$

- Lebar baterai/aki $=15 \mathrm{~cm}$

- Tinggi baterai/aki $=9,5 \mathrm{~cm}$

- Berat baterai/aki $=8 \mathrm{~kg}$

- Tegangan baterai/aki $=24$ Volt

5. Berat Kendaraan

M.sepeda $=\mathrm{M} 1+\mathrm{M} 2+\mathrm{M} 3+\mathrm{M} 4$

$$
\begin{aligned}
& =20+2,5+0,1+8 \\
& =30,6 \mathrm{~kg}
\end{aligned}
$$

\section{B. Prinsip kerja alat}

1. Adapun model kendaraan yang akan digunakan untuk sepeda listrik

2. Energi kinetik yang dihasilkan sepeda membuat generator berputar sehingga generator mengkonversi energi gerak menjadi energi listrik.

3. Energi listrik yang di hasilkan oleh generator dialirkan ke baterai melalui baterai change regulator (BCR), untuk menambah kebutuhan arus yang dipakai.

4. Energi listrik yang telah dikonversi dari generator disimpan ditempat penampungan (berupa baterai/aki).

5. Energi listrik yang disimpan di baterai/aki, disuplay ke motor agar motor dapat berputar

6. Sebelum disuplay ke motor, ada berupa saklar (switching controll) untuk mengatur putaran motor.

7. Kemudian tidak lupa membuatkan terminal/port untuk pengisian baterai menggunakan listrik dari tegangan jala-jala PLN apabila sepeda sedang tidak bergerak atau dengan kata lain disimpan.

C. Hasil perhitungan untuk beban $50 \mathrm{Kg}$

1. Massa Sistem Kendaraan

M.total $=$ berat total sepeda + berat pengendara

$=30,6+50$

$=80,6 \mathrm{~kg}$

Dimana :

W.tot $=80,6 * 9,8$

$=789,88 \mathrm{~N}$

2. Daya Mekanik

- Gaya Normal $\left(\mathrm{F}_{\mathrm{N}}\right)$

$\mathrm{FN}=$ M.tot $* 9,8$

$=80,6 * 9,8$

$=789,88 \mathrm{~N}$

- Gaya gesek statik (FS)

$\mathrm{FS}=\mathrm{FN} * \mu \mathrm{S}(0,7)$

$=789,88 * 0,7$

$=552,916 \mathrm{~N}$

- Gaya gesek kinetic

$\mathrm{FK}=\mathrm{FN} * \mu \mathrm{K}(0,6)$

$=789,88 * 0,6$

$=473,928 \mathrm{~N}$ 
- Torsi yang dipelukan untuk menggerakkan sepeda harus lebih besar dari pada

TS $>$ FS * R.roda

$$
=552,916 * 0,25
$$

$=138,229 \mathrm{~N}$

- Agar sepeda bergerak, maka gaya pedal kaki harus lebih besar dari pada

$\mathrm{F}>\mathrm{TS} / \mathrm{R} . \mathrm{PS}$

$=552,916 / 0,2$

$=2.764,58 \mathrm{~N}$

- Setelah sepeda bergerak, maka gaya $(\mathrm{F})$ yang diperlukan menjadi

$\mathrm{F}=(\mathrm{FK} * \mathrm{R} . \mathrm{PS}) / \mathrm{R}$. roda

$=(473,928 * 0,2) / 0,25$

$=379,1424 \mathrm{~N}$

3. Torsi Motor Listrik

$$
\begin{aligned}
\mathrm{T}_{\cdot \text { motor }} & =\frac{60 * P}{2 * \pi * n} \\
& =\frac{60 * 350}{2 * 3,14 * 3000} \\
& =1,1146 \mathrm{Nm}
\end{aligned}
$$

4. Daya yang dihasilkan motor listrik untuk menggerakkan sepeda

$$
\begin{aligned}
\mathrm{P} . \text { out } & =9,8 * \mu * \mathrm{M} . \text { tot } * \mathrm{v} \text {. rata }- \\
\text { rata } & \frac{100}{\eta} \\
& =9,8 * 0,06 * 80,6 * \\
5,68 * & \frac{100}{85} \\
& =316,6954 \text { Watt }
\end{aligned}
$$

5. Kecepatan Tempuh Sepeda

Untuk Jarak 100 meter

$$
\begin{aligned}
\mathrm{v}=\frac{s}{t} & \\
= & \frac{100}{18} \\
& =5,55 \mathrm{~m} / \mathrm{s}
\end{aligned}
$$

\section{KESIMPULAN}

Dalam perancangan dan pembuatan sistem penggerak sepeda listrik, digunakan beberapa komponen pendukung untuk menkonversi energi kinetik dari gesekan roda ban menjadi energi listrik agar dapat digunakan motor sebagai sumber energi penggerak. Untuk menjalankan sepeda listrik, Menggunakan: (Generator DC Magnet Permanent, BCR, Charge PLN, Accu/aki, switching controll, Motor DC Seri)

Cara kerja dari sepeda listrik pemanfaatan generator DC magnet permanent sebagai sumber energi penggerak Sepeda adalah kinetik yang hasilkan dari roda ban membuatgenerator DC berputar sehingga mengkonversi dari energi gerak menjadi energi listrik. Kemudian dialirkan ke baterai change regulator (BCR), untuk menambah arus yang dipakai. Dalam mendukung penyedian sumber energi listrik, pada sepeda listrik dipasangkan sambungan berupa (charge) dari energi listrik yang bersumber dari PLN, Sebagai sumber energi alternatif pada sepeda listrik. Energi listrik yang telah dikonversi disimpan ditempat penampungan (berupa ACCU/aki). Listrik yang disimpan di ACCU/aki, disuplay ke motor. Agar motor dapat berputar. Sebelum disuplay ke motor, ada berupa saklar (switching controll) untuk mengatur putaran motor.

\section{DAFTAR ACUAN}

[1] S. A. dan Y. E. A. R. Sulistiyono, "Studi Potensi Pembangkit Listrik Tenaga Mikrohidro (PLTMH) di Sungai Cikawat Desa Talang Mulia Kecamatan Padang Cermin Kabupaten Pesawaran Provinsi Lampung, Universitas Lampung.,” 2013.

[2] B. dkk Nainggolan, "Rancang Bangun Sepeda Listrik Menggunakan Panel Surya Sebagai Pengisi Baterai," J. Media, Politeknologi Vol.15 No.3 jakarta., 2016.

[3] D. dkk Satria, "Analisa Perhitungan Energi Listrik Pada Sepeda Listrik Hybrid," J. Media, Hal 9 - 19 Fak. Tek. Univ. Sultan Ageng Tirtayasa. Cilegon, Banten, Indones., 2017.

[4] A. Prakoso, "Prototype Sistem Penggerak Mobil Listrik Dengan Memodifikasi Mobil Mainan Dengan Pemanfaatan Solar Cell Sebagai Sumber Energi Penggerak," Tugas akhir. Fak. Tek. Univ. Halu oleo. Kendari, Sulawesi Tenggara, Indones., 2015.

[5] Sularso dan Kiyokatsu Suga, "Dasar Perencanaan Dan Pemilihan Elemen Mesin," in PT. Pradnya Paramita, Jakarta, 1983.

[6] R. Hidayat, "pengertian dan fungsi baterai (aki)". http://www.kitapunya.net/2013/12/pengertian-danfungsi-baterai-aki.html," in Diakses 10 Januari 2018, 2013.

[7] A. zona Elektro, "Motor Listrik, Prinsip Kerja Motor Listrik Dan Jenis motor Listrik". http://zonaelektro.net/motor-listrik/," in Diakses 11 januari 2018 , .

[8] Dunia listrik, “Animasi Motor DC". http://dunialistrik.com/2009/09/animasi-motor-dc.html," diakses 12 Januari 2018. 2008.

[9] Mukhlis, "pengertian dan prinsip kerja generator". http://www.masuklis.com/2014/05/pengertiangenerator-prinsip-kerja.html," Diakses 13 Januari 2018. 2015. 